\title{
An Empirical Study of the EFQM Excellence Model in Iran
}

\author{
Nour Mohammad Yaghoubi (PhD) \\ Department of Management, University of Sistan and Baluchestan, Zahedan, Iran \\ E-mail: yaghoobinor@yahoo.com
}

Maryam Bandeii (MSc) (Corresponding author)

Master Student of Management, Sistan and Baluchestan, Zahedan, Iran

Jamshid Moloudi (MSc)

Master Student of public administration, University of Sistan and Baluchestan, Zahedan, Iran

Received: November 12, $2010 \quad$ Accepted: December 9, 2010 doi:10.5539/ijbm.v6n5p260

\begin{abstract}
Performance assessment and identify areas to improve for survive need to organized framework that to be able to analysis and to evaluate its environment conditions continuously. One of these tools for assessment is EFQM model that on the one hand to assess today's performance and situation and identify area to improve and on the other hand the map and guide of act of organizations for pay attention to effective factors, finding strong points and improve areas. The study was planned to ascertain Effect of implementation of EFQM excellence model. In present research the sample size consists of 103 employees (13 women and 90 men) that were selected at random from employee of Power comon 3)-Iran. The T-test was used to analyze the data. The results of present study were illustrated that the rate of change in the present organization after implementation EFQM model cause to developed organization in Dimensions of excellence model (Leadership, policy and strategy, human resource, resources, processes, customer, results, employee results, leadership results, performance results) $(p<0.01)$.
\end{abstract}

Keywords: Excellence model, EFQM, Empowerment criteria, Result criteria, Self-assessment, MBNQA model

\section{Introduction}

Instruments are always interested to assess "who they are", because it is thought that if we know "how" then we can plan and discussion make better for the future activity (Najmi \& Hossaini, 2004). Expansion and complexity of goals, processes and organizational structure in the competitive environment, the organizations can continue to survive tempered that be accountable to expectations and needs of customers. Likewise, profitability and wealth creation pay attention as the main and superior factors of organization. In the every organization Managers are concerned about their results and to seek solutions to improve the performance and usually try to have control by measurement systems of performance on the organizational activities (Bozorgi, 2004; Delghavi, 2007).

The recent studies are illustrated that performance measurement by traditional methods which is based on management accountability system are inappropriate. Wangrassamee (2003) has identified performance measurement by traditional method is in consistent with accept thinking constantly improve, it is difficult to use in practice, its flexibility is low, it is neglect to meet the needs of customers and cannot be combined with organizational strategies (Wangrassamee, 2003). Can be said that the aim of traditional method judgments and recall performance by looking at past. In the modern attitude is considered to growth and development with look to the future (Eftekhari, 2002; Shertan, 2008). There are different methods for organizational performance evaluation that each of them has their advantage and disadvantage. If we can run the same approach for organizations and companies therefore will provide the possibility to compare between them. This approach should be systematic and comprehensive vision to all of performance area of organization and also it should consider all inputs, implementation process, output and results of activities of each organization and their impact on other (Rooghani \& homayonfar, 2005; Mohebi, 2008). 


\section{Literature Review}

One of the best ways for organizational assessment is self-assessment that the EFQM model has special attention to it (Najmi \& Hossaini, 2004; Javidi, 2006).There are 9 criteria in this model that the 5 criteria of it is related to empowerments and the 4 other criteria are considered the results (Bozorgi, 2004; Jelodar, 2006), all of the criteria have 1000 scores (500 scores for empowerments and 500 other scores for the results), if an organization can perform it completely, can be get 1000 scores. The European organizations can apply EFQM to self-assessment annually (Najmi \& Hossaini, 2004; Shertan, 2008). Nearly two years, in the Iranian organizations use based on present model to organizational assessment (Najmi \& Hossaini, 2004; Razani, 2002). With rapid spread and its application in many European countries, in our country was also realized to importance of EFQM in order to enter to global markets and maintain comparative advantage in industry. Look at the values and fundamental concepts of EFQM model in Iran that was taken from European United attempts and experiences is illustrated that the main and basic concepts of business has been considered in the present model.

The business excellent models offer method of an organization that it is excelled in the idea and practice than other organizations and it show in the competitive environment how must apply for growth, survive and superiority. Nowadays, may global countries award prizes by using of this model that it is stimulant for organizations toward Eminent and Wealth Creation. At the same time, the European EFQM model has been admitted popularity in the world and it was model of many countries for making and designing the national prizes (Pouyan \& Karimanpoor, 2007). EFQM model is specially tools the using by organizations for performance assessment and it is the basis to make common language and thinking and building a structure to management system that for removing re-workings and detect deviations (Bozorgi, 2004; Homayonfar, 2008). Nowadays, many organizations have done attempts to use this model. In the some of them use perspective of present model for self-assessment, determine strengths and improvement areas and Holistic definition of improvement projects, but others of them have little information about EFQM and its advantages (Assefi, 2007).

Organizational Excellent: the index activities in organization with using of organizational results, focus on customer, leadership and agreement, management basis on processes and facts and employees participation, continuous improvement and innovation, common profit among of stakeholders and social responsibility (Mir bagheri, 2002; Najmi \& Hosseini, 2006).the other definition of organizational excellent is included: Outstanding performance in manage organization and achieve results based on fundamental conceptions is included: result oriented, customer oriented, leadership and target stabilization, processes and facts, employees participation, continuous improvement and innovation, of course, partnerships is acceptable which is profitability for both sides and social responsibility (EFQM, 2005). diagram (1) is showed the excellence path for each organization(See the diagram (1) in appendix).

The EFQM model definite superior management and excellent organization, and beforehand this way are said that moving toward this path is very difficult even in the best situations (Najmi \& Hosseini, 2006). Also, in the global competition situation, technological changes, continuous changes in economic, social conditions and environment of customer can be said that moving on this way may be more difficult. With recognizing these challenges created European Foundation of Quality Management (Najmi \& Hosseini, 2006; Mirbagherri, 2002; Amiri \& Ssokaki, 2005).

The most important organizational excellence patterns: self-assessment is the new concept that nowadays use to problems identity and performance assessment (Pouyan \& Kariman poor, 2007). CEOs believe assessment systems that existing in the world as performance excellence model of "Balrdige", "Dominik" and "EFQM" models are strong tools to assessment that help to recognize strong and threat points of organization in the work areas and reviewing whether organization is in the right way and to move right or not (Arora, 1998).

Many European organizations have positive imagine from quality. European organizations increasingly have accepted quality management as major strategy for increasing and developing their situation in the market and obtaining financial results. In 1998, some of them had felt in the quality management specially needed to begin a European move, created an institution and called it "European Foundation of Quality Management" (Delghavi, 2007).

The EFQM model has introduced as privative framework for assessment and development of organizations, this method was illustrated stable advantage that lots of organizations must obtain them (Hillman, 1994).organizational excellence model (EFQM) is a completion and comprehension way to provide confidence success in long-term. This method is recognition tool for self-assessment in the organization. The organizations can effectively create balance among of opportunity and resource allocated and real business plans. The findings were showed that this model is more successful in the private sectors than the public sectors (Asare, 2001). 
Other studies in this field were identified that about 69 percent of European organizations use this model for self-assessment. Excellence model contain about 9 criteria that to divide to 2 sectors that are following:

1) Empowerment criteria

- Leadership

- Policy and strategy

- Employee

- Participations and resource

- Process

2) Result criteria

- Customer results

- Employee results

- Social results

- Key performance results (See the Fig (1) in appendix).

Advantage of excellence model (EFQM): The organizational excellence model is systematic and non-prescription model that pay to assessment of internal facts and processes and results. Also, in this assessment the employees deal with and participate with them. The most important profit of this method is recognition of strong and weakness points of organization and employees of organization that it help to organizational development and it provide an opportunity for use experiences of employees (Tajri, ،2005).

Other advantages of EFQM model are following:

- Management basis on organizational process.

- Special attention to assessment basis on facts.

- Obtain results by organization.

- Using of self-assessment approach in order to organization excellence (Industrial engineering, 2005).

Performance improvement is high on the agenda of many companies around the world and with the growing number of improvement models now available care has to be taken to adopt an approach that will yield the most attractive return on investment. Wongrassamee, Simmons and Gardiner (2003) were studied about Performance measurement tools: the Balanced Scorecard and the EFQM Excellence Model. The paper concludes that it is difficult to find a perfect match between a company and a performance measurement framework and that further research should concentrate on how to implement strategic performance frameworks effectively in specific types of organization. Bou-Llusar and et al. (2009) were studied about an empirical assessment of the EFQM Excellence Model: Evaluation as a TQM framework relative to the MBNQA Model. Based on responses collected from managers of 446 Spanish companies by means of a structured questionnaire, we find that: (a) social and technical dimensions are embedded in the model; (b) both dimensions are inter-correlated; (c) they jointly enhance results. These findings support the EFQM Excellence Model as an operational framework for TQM, and also reinforce the results obtained in previous studies for the MBNQA, suggesting that quality award models really are TQM frameworks.

\section{Research Questions}

1) Is implementation of EFQM model of the respondents view Cause to improve the leadership of organization?

2) Is implementation of EFQM model of the respondents view Cause to improve the policy and strategy of organization?

3) Is implementation of EFQM model of the respondents view Cause to improve the human resource (employee) of organization?

4) Is implementation of EFQM model of the respondents view Cause to improve the resources of organization?

5) Is implementation of EFQM model of the respondents view Cause to improve the processes of organization?

6) Is implementation of EFQM model of the respondents view Cause to improve the customer results of organization?

7) Is implementation of EFQM model of the respondents view Cause to improve the employee results of organization? 
8) Is implementation of EFQM model of the respondents view Cause to improve the leadership results of organization?

9) Is implementation of EFQM model of the respondents view Cause to improve the key performance results of organization?

\section{Methodology}

Power department of sistan and baluchestan (region 3) is one of public organizaton in Iran that established in 1981. This organization is implemented the EFQM model for assessment of performance in 2003. Data for this study was collected by the questionnaires of EFQM that contained 45 items and also, for assess scale of EFQM of organization that was respondent by employee of Power department of sistan and baluchestan (region 3) - Iran. The questionnaires used 5 point likert scales ( 1 represent strongly disagree and 5 represent strongly agree) to measure the construct. Cronbach's $\alpha$ for this scale was 0.87 to EFQM questionnaire respectively. Data analysis was carried out by using the statistical program packages SPSS. Among the respondent, $87.38 \%$ was male and $12.62 \%$ female. Majority of the respondent are in the middle age which is between 30 to 40 years $(63.1 \%) .31 \%$ has been working with the organization for more than 15 years, $32.1 \%$ have been working between 10 to 15 years, $29.7 \%$ have been working between 5 to 10 years and $7.2 \%$ have been working less than 5years. Majority of the respondent have masters and bachelors degree (46.2\%).

\section{Examine of Questions}

The results of Table-1 show (See the table.1 in appendix) that after implementation of EFQM model in the present organization, the mean score is (7.9320). Also, according to the rate of $\mathrm{T}$ obtained $(\mathrm{t}=3.620)$, can be said that the rate of change in this organization after implementation EFQM model cause to developed leadership in organization. So, this change contained positive impact on leadership of organization $(\mathrm{P}<0.001)$.

The results of Table-2 show (See the table.2 in appendix) that after implementation of EFQM model in the present organization, the mean score is (10.0971). Also, according to the rate of $\mathrm{T}$ obtained $(\mathrm{t}=3.89)$, can be said that the rate of change in this organization after implementation EFQM model cause to developed policy and strategy of organization in organization. So, this change contained positive impact on policy and strategy of organization $(\mathrm{P}<0.001)$.

The results of Table-3 show (See the table.3 in appendix) that after implementation of EFQM model in the present organization, the mean score is (6.4272). Also, according to the rate of $\mathrm{T}$ obtained $(\mathrm{t}=3.823)$, can be said that the rate of change in this organization after implementation EFQM model cause to developed policy and strategy of organization in organization. So, this change contained positive impact on human resource of organization $(\mathrm{P}<0.001)$.

The results of Table- 4 show (See the table.4 in appendix) that after implementation of EFQM model in the present organization, the mean score is (7.8350). Also, according to the rate of $\mathrm{T}$ obtained $(\mathrm{t}=3.63)$, can be said that the rate of change in this organization after implementation EFQM model cause to developed policy and strategy of organization in organization. So, this change contained positive impact on resources of organization $(\mathrm{P}<0.001)$.

The results of Table-5 show (See the table.5 in appendix) that after implementation of EFQM model in the present organization, the mean score is (11.6019). Also, according to the rate of $\mathrm{T}$ obtained $(\mathrm{t}=5.714)$, can be said that the rate of change in this organization after implementation EFQM model cause to developed policy and strategy of organization in organization. So, this change contained positive impact on processes of organization $(\mathrm{P}<0.001)$.

The results of Table-6 show (See the table.6 in appendix) that after implementation of EFQM model in the present organization, the mean score is (12.8932). Also, according to the rate of $\mathrm{T}$ obtained $(\mathrm{t}=4.812)$, can be said that the rate of change in this organization after implementation EFQM model cause to developed policy and strategy of organization in organization. So, this change contained positive impact on customer results of organization $(\mathrm{P}<0.001)$.

The results of Table-7 show (See the table.7 in appendix) that after implementation of EFQM model in the present organization, the mean score is (7.9320). Also, according to the rate of $\mathrm{T}$ obtained $(\mathrm{t}=3.658)$, can be said that the rate of change in this organization after implementation EFQM model cause to developed policy and strategy of organization in organization. So, this change contained positive impact on employee results of organization $(\mathrm{P}<0.001)$. 
The results of Table- 8 show (See the table. 8 in appendix) that after implementation of EFQM model in the present organization, the mean score is (3.3883). Also, according to the rate of $\mathrm{T}$ obtained $(\mathrm{t}=3.688)$, can be said that the rate of change in this organization after implementation EFQM model cause to developed policy and strategy of organization in organization. So, this change contained positive impact on leadership results of organization $(\mathrm{P}<0.001)$.

The results of Table- 9 show (See the table.9 in appendix) that after implementation of EFQM model in the present organization, the mean score is (5.4757). Also, according to the rate of $\mathrm{T}$ obtained $(\mathrm{t}=7.261)$, can be said that the rate of change in this organization after implementation EFQM model cause to developed policy and strategy of organization in organization. So, this change contained positive impact on key performance results of organization $(\mathrm{P}<0.001)$.

\section{Conclusion}

The results from questions distributed and collected and 45 key questions related to organizational excellence model EFQM in the empowerment section (including: Leadership, policy and strategy, human resource, resources, processes), results section (including: customer, results, employee results, leadership results, performance results) and statistical analysis were illustrated that there is improvement in the organization.

In confirmation of results obtained through questions can be pointed to the comparison evolution company in 2006 and 2008 by consulting company. Total points resulted from company assessment in 2006 and 2008 were 168 and 235 orderly. This compression was showed that there is growth about 40 percent and continuous improvement in organization. Also, the findings of the present study are in conformity with researches of Wongrassamee, Simmons and Gardiner (2003), Bou-Llusar and et al. (2009) and other researchers who study EFQM model for organizational development. Also, present study is suggested to some of organizations that if you want to complete in the dynamic and complex environment, you certainly need to implement EFQM in your organization, because it is inevitable.

\section{References}

Amiri, M., \& S.M. Sokaki, (2004). Organization Performance Evaluation Guide based on EFQM model. Tehran Statistical publication, first edition, (In Persian).

Arora, K.C. (1998). Total quality management and ISO 14000, Delhi.

Asore, A. (2002). The need education and training in the use of the EFQM mode. Quality assurance in education, Vol. 10, No. 1.

Assefi, H. (2007). Presented a model of integrated risk management and EFQM model in order to increase organizational performance. Intelligent industry magazine, No. 96, (In Persian).

Bozorgi, F. (2004). Principle and basics theoretical excellence model. Management, No. 89-90, (In Persian).

Delghavi, A. (2007). Principle and basic of organizational excellence model in 2003 by Baldrige. Science committee (In Persian).

EFQM. (2006). Familiarity with excellence model. [Online] Available: www.INQA.org.

Eftekhari, H. (2002). Evaluation performance Executive device. Development management, No. 58, (In Persian).

Forghani, M. (2006). Provide successful experiences of organizational excellence. Tadbir magazine, No. 167, (In Persian).

Hellman, G.P. (1994). Making self-assessment successful. The TQM magazine, Vol. 6.

Homayonfar, M. (2008). Excellence Pioneers. Saramad publication, (In Persian).

Hossaini, S., \& M. Najmi, (2004). Excellence model EFQM from idea to practice. Saramad paublication, Seventh edition (In Persian).

Industrial engineering. (2005). Familiarity with EFQM model. [Online] Available: www.Industrymihanblog.com.

J. Carlos Bou-Llusar, Ana B. Escrig-Tena, Vicente Roca-Puig, Inmaculada Beltra' n-Martı'n. (2009). An empirical assessment of the EFQM Excellence Model: Evaluation as a TQM framework relative to the MBNQA Model. Journal of Operations Management, NO: 27.

Javidi, H. (2006). Familiarity with organizational excellence based on EFQM model. World top quality, No. 8, (In Persian). 
Jelodar, B. (2006). Organizational Excellence EFQM. Iran industrial research and education center publication, second edition, (In Persian).

Mirbagherri, S.M. (2002). Organizational excellence. Tadbir magazine, No. 125, (In Persian).

Moeller, J. (2000). Quality management in German health care the EFQM excellence model. Emerald, international journal of health care quality assurance, Vol. 13, Issue: 6 .

Mohebi, A.A. (2002). Organizational excellence model EFQM, tactics and executive approach. Yase behesht, (In Persian).

Pouyan, A., \& M. Karimanpoor, (2007). Establishment of organizational excellence model EFQM in services companies. Journal of industrial engineering perspective, No. 68, (In Persian).

Razani, A. (2002). Familiarity with EFQM model. Imam publication, first edition, (In Persian).

Rooghani, M., \& M. Homayonfar, (2005). Self-assessment questionnaire based on excellence model. Human Resource productivity institution, (In Persian).

S. Wongrassamee, J.E.L. Simmons, P.D. Gardiner, (2003). Performance measurement tools: the Balanced Scorecard and the EFQM Excellence Model. Measuring Business Excellence, Vol. 7 Iss: 1, pp.14 - 29

Shertan, R. (2008). Learning to implement self-assessment based on EFQM model. Sixth international conference on management, (In Persian).

Tajri, M. (2005). Evaluation EFQM model in organization. Management, No. 101-102.

Table 1. Sample T-test of Leadership of organization after implementation EFQM model $(\mathbf{n}=\mathbf{1 0 3})$

\begin{tabular}{|l|c|c|c|c|c|c|}
\cline { 2 - 7 } \multicolumn{1}{c|}{} & Mean & S.D. & Mean Difference & Sig. (2-tailed) & t & df \\
\hline leadership of organization & 7.9320 & 1.20670 & 0.43204 & .000 & 3.620 & 102 \\
\hline
\end{tabular}

Table 2. Sample T-test of policy and strategy of organization of organization after implementation EFQM model $(\mathbf{n}=\mathbf{1 0 3})$.

\begin{tabular}{|c|c|c|c|c|c|c|}
\cline { 2 - 7 } \multicolumn{1}{c|}{} & Mean & S.D. & Mean Difference & Sig. (2-tailed) & t & df \\
\hline $\begin{array}{c}\text { policy and strategy of } \\
\text { organization }\end{array}$ & 10.0971 & 2.87830 & 1.09709 & .000 & 3.89 & 102 \\
\hline
\end{tabular}

Table 3. Sample T-test of human resource of organization of organization after implementation EFQM model $(\mathbf{n}=\mathbf{1 0 3})$.

\begin{tabular}{|c|c|c|c|c|c|c|}
\cline { 2 - 7 } \multicolumn{1}{c|}{} & Mean & S.D. & Mean Difference & Sig. (2-tailed) & t & df \\
\hline $\begin{array}{c}\text { human resource of } \\
\text { organization }\end{array}$ & 6.4272 & 1.13416 & 0.42718 & .000 & 3.823 & 102 \\
\hline
\end{tabular}

Table 4. Sample T-test of resources of organization of organization after implementation EFQM model ( $\mathrm{n}=103)$.

\begin{tabular}{|c|c|c|c|c|c|c|}
\cline { 2 - 7 } \multicolumn{1}{c|}{} & Mean & S.D. & Mean Difference & Sig. (2-tailed) & T & df \\
\hline resources of organization & 7.8350 & 1.02992 & 0.33495 & .001 & 3.63 & 102 \\
\hline
\end{tabular}

Table 5. Sample T-test of processes of organization of organization after implementation EFQM model ( $\mathrm{n}=103)$.

\begin{tabular}{|c|c|c|c|c|c|c|}
\cline { 2 - 7 } \multicolumn{1}{c|}{} & Mean & S.D. & Mean Difference & Sig. (2-tailed) & t & df \\
\hline processes of organization & 11.6019 & 1.95709 & 1.10194 & .000 & 5.714 & 102 \\
\hline
\end{tabular}


Table 6. Sample T-test of customer results of organization of organization after implementation EFQM model $(n=103)$.

\begin{tabular}{|c|c|c|c|c|c|c|}
\cline { 2 - 7 } \multicolumn{1}{c|}{} & Mean & S.D. & Mean Difference & Sig. (2-tailed) & $\mathbf{t}$ & df \\
\hline $\begin{array}{c}\text { customer results of } \\
\text { organization }\end{array}$ & 12.8932 & 1.88863 & 0.68835 & .000 & 4.812 & 102 \\
\hline
\end{tabular}

Table 7. Sample T-test of employee results of organization of organization after implementation EFQM model $(n=103)$.

\begin{tabular}{|c|c|c|c|c|c|c|}
\cline { 2 - 7 } \multicolumn{1}{c|}{} & Mean & S.D. & Mean Difference & Sig. (2-tailed) & $\mathbf{t}$ & df \\
\hline $\begin{array}{c}\text { employee results of } \\
\text { organization }\end{array}$ & 7.9320 & 1.19855 & 0.43204 & .000 & 3.658 & 102 \\
\hline
\end{tabular}

Table 8. Sample T-test of leadership results of organization of organization after implementation EFQM model $(n=103)$.

\begin{tabular}{|c|c|c|c|c|c|c|}
\cline { 2 - 7 } \multicolumn{1}{c|}{} & Mean & S.D. & Mean Difference & Sig. (2-tailed) & $\mathbf{t}$ & df \\
\hline $\begin{array}{c}\text { leadership results of } \\
\text { organization }\end{array}$ & 3.3883 & 1.06856 & 0.38835 & .000 & 3.688 & 102 \\
\hline
\end{tabular}

Table 9. Sample T-test of key performance results of organization of organization after implementation EFQM model $(\mathrm{n}=103)$.

\begin{tabular}{|c|c|c|c|c|c|c|}
\hline & Mean & S.D. & Mean Difference & Sig. (2-tailed) & t & df \\
\hline Key performance results & 5.4757 & 1.36371 & 0.97573 & .000 & 7.261 & 102 \\
\hline
\end{tabular}

\section{APPENDIX}

\section{Excellence}

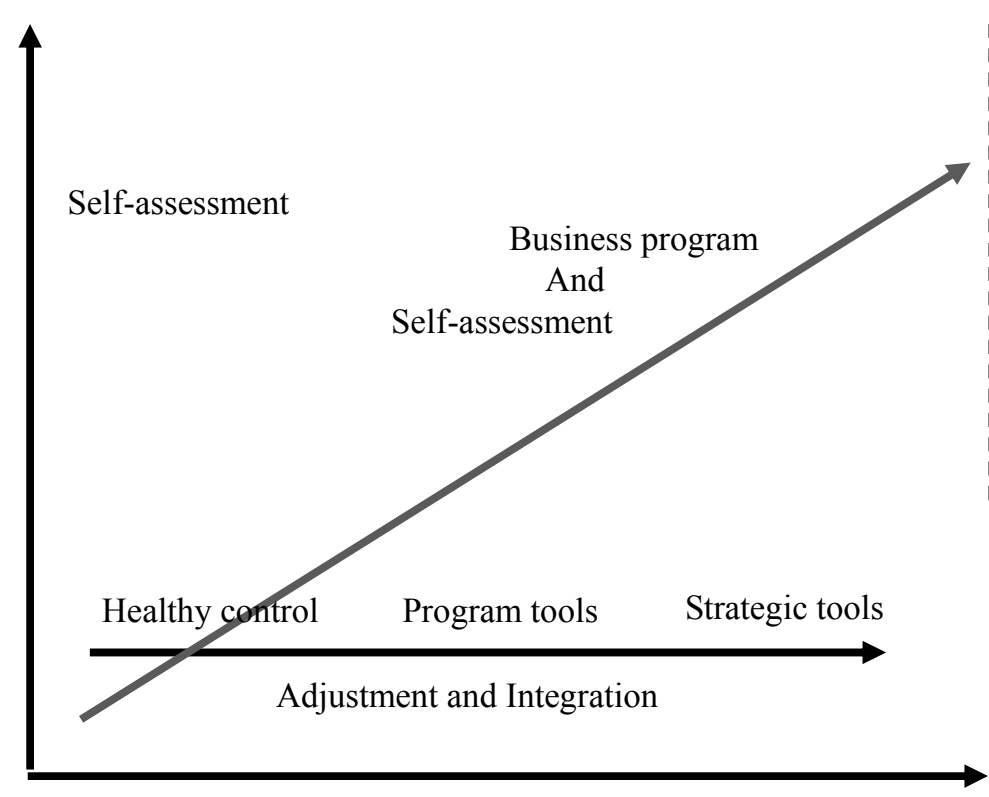

Diagram 1. Excellence path of each organization cited of: Forgani, 2006, 56 


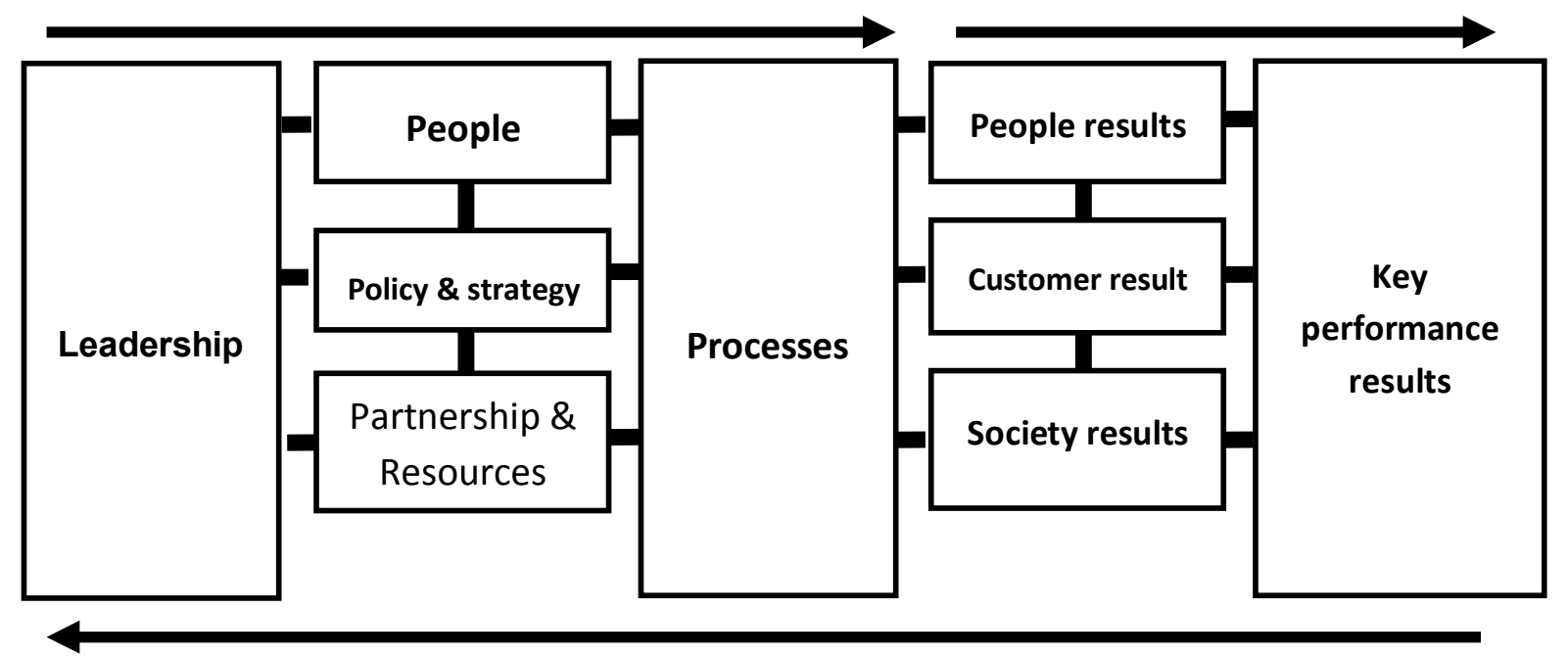

Figure 1. Cited of Moeller, 2000: 6 